\title{
CITIZEN PROFILES OF RESIDUAL WASTE SEPARATION BEHAVIOUR
}

\author{
Kamoen, Ceri (1); \\ Karahanoglu, Armagan (2) \\ 1: University of Twente, Industrial Design Engineering, Enschede, Netherlands; \\ 2: University of Twente, Interaction Design Research Group, Enschede, Netherlands
}

\begin{abstract}
The impact of human behaviour on climate change is getting more apparent every day. Citizens are encouraged and sometimes forced to change their waste separation behaviour to reduce their effect on this global challenge. One way to achieve this is to reduce the amount of fine and bulky residual waste that ends in landfill or is incinerated. Studies show that this can be achieved by active, efficient, and correct household participation. Multiple intervention strategies are being tried out, while the European Union statistics show that the numbers are not at the desired level yet. To improve the waste separation practices, understanding the motivation and drivers of (correct) waste separation behaviour is of high importance for the current strategies' success. In this paper, based on the Self-Determination Theory, we propose "citizen-profiling" framework, which consists of six citizen profiles, that illustrates citizens' motivations and drivers of residual waste separation behaviour. We end this paper, with discussions on motivating the citizens to contribute to waste separation actively.
\end{abstract}

Keywords: Sustainability, Human behaviour in design, User centred design

\section{Contact:}

Karahanoglu, Armagan

University of Twente

Design, Production and Management

Netherlands, The

a.karahanoglu@utwente.nl

Cite this article: Kamoen, C., Karahanoglu, A. (2021) 'Citizen Profiles of Residual Waste Separation Behaviour', in Proceedings of the International Conference on Engineering Design (ICED21), Gothenburg, Sweden, 16-20 August 2021. DOI:10.1017/pds.2021.63 


\section{INTRODUCTION}

Climate change has become the most significant societal challenge of the 21st century (Biesbroek et al., 2010). Governments enforce companies, organisations, and citizens to think consciously about the planet's future and make sustainable choices accordingly. One way to be more sustainable is to reduce the effect of incineration of residual household waste and carbon emission (Beylot and Villeneuve, 2013; Istrate et al., 2020). To achieve this, the amount of domestic fine residual waste needs to be minimized, which requires improvement in the citizens' household waste separation and sorting practices (Rousta et al., 2015). European Union (EU) countries have already set goals for reducing the amount of residual household waste. In the EU, $492 \mathrm{~kg}$ of municipal waste was generated per capita in 2018 , of which $47 \%$ was recycled (Eurostat, 2020). However, the EU aims to recycle at least $60 \%$ of municipal waste by 2025 and $65 \%$ by the year 2030 (Árnadóttir et al., 2019).

While these goals are promising, studies show that the amount of domestic fine and bulky residual waste is not at the desired level yet (Morlok et al., 2017). Processing techniques for waste separation require proper waste separation at the source (e.g., homes), which entails active and efficient household participation (Rousta et al., 2015). However, not all citizens have the motivation to separate waste, and some have limited waste separation knowledge. Promotion of waste separation behaviour requires understanding the citizens' compliance. While design research can promote citizens' waste separation behaviour, the knowledge of strategies and drivers affecting residual waste separation behaviour is fragmented.

To address this, we combine theory with strategies and drivers of waste separation behaviour and illustrate the citizen profiles for waste separation behaviour. For an individual to perform a behaviour, the person's motivation is of high importance (Bandura, 2001; Deci and Ryan, 2008). We leverage this, and we merge the notion of (1) Self-Determination Theory and its adjunct-theories with (2) the drivers that affect compliance with waste separation behaviour at home and (3) behaviour intervention strategies. This paper's contribution is to illustrate the citizen profiles that articulate the motivations of waste separation behaviour and the strategies that could guide the promotion of this behaviour. We end the paper ends with suggestions for future utilisation of the citizen profiles.

\section{REGULATION OF WASTE SEPARATION MOTIVATION}

Self Determination Theory (SDT) explains three basic psychological human needs that innate motivation (Ryan and Deci, 2000): (1) autonomy (i.e., the need to control one's actions), (2) competence (i.e., the need to be effective in dealing with the environment), and (3) relatedness, (i.e., the need to have close and affectionate relationships with others) (Deci and Ryan, 1980, 2008). Deci and Ryan expanded their earlier works of SDT with two adjunct-theories: Cognitive Evaluation Theory (CET) (Deci et al., 1975; Deci and Ryan, 1980), in which they introduced different types of motivation (i.e., intrinsic, extrinsic, and a-motivation) as the drivers of behaviour, and Organismic Integration Theory (OIT) (Deci and Ryan, 1985; Ryan and Connell, 1989) in which they articulated people's behaviour internalisation (e.g., taking in a value or regulation) and integration (e.g., a further transformation of that regulation into their self) process.

According to CET, intrinsic motivation contains internal benefits (e.g., being proud of achievement) and is supported by the experience of interest and enjoyment of the behaviour itself. Extrinsic motivation recalls external factors to ensure a behaviour (e.g., incentives, rewards, etc.). Individuals can be a-motivated when they see no value in performing the behaviour or feel that they cannot achieve the desired outcome. A-motivation results in non-intention to perform the desired behaviour. The non-performance could be due to the lack of contingency (Miller and Seligman, 1975; Rotter, 1966) and perceived competence (Bandura, 1977; Deci, 1975). To exemplify, intrinsically motivated people separate their waste because it gives them inherent satisfaction. Extrinsically motivated people separate their waste for the sake of its financial turnover, while a-motivated people believe that waste separation is useless and therefore do not separate their waste.

According to Deci and Ryan (2000), an individual can follow six different behaviour regulation styles to internalise a behaviour (Table 1). In the table below, we exemplified these regulation styles, which we believe are essential to comprehend, to design for promoting waste separation behaviour. In Section 4, we will use these styles in describing the citizen profiles of waste separation behaviour. 
Table 1. Types of behaviour regulation (Ryan and Deci, 2000)

\begin{tabular}{|l|c|c|r|}
\hline $\begin{array}{l}\text { Self- } \\
\text { determination }\end{array}$ & Type of regulation & Regulation style & Example \\
\hline A-motivation & Non-regulation & $\begin{array}{c}\text { Failure to act or acting passively } \\
\text { to perform the behaviour }\end{array}$ & $\begin{array}{r}\text { I don't believe a need } \\
\text { to separate waste. }\end{array}$ \\
\hline \multirow{4}{*}{$\begin{array}{l}\text { Extrinsic } \\
\text { Motivation }\end{array}$} & External regulation & $\begin{array}{c}\text { Action to satisfy an external } \\
\text { demand or a social event }\end{array}$ & $\begin{array}{r}\text { Waste separation } \\
\text { costs less money than } \\
\text { not separating waste. }\end{array}$ \\
\cline { 2 - 4 } & Introjected regulated & $\begin{array}{c}\text { Motivation is regulated by } \\
\text { avoiding guilt, shame, or feel } \\
\text { worthy and other ego } \\
\text { improvements }\end{array}$ & $\begin{array}{r}\text { My family members } \\
\text { shame me when I do } \\
\text { not separate my }\end{array}$ \\
\cline { 2 - 4 } & $\begin{array}{c}\text { Regulation through } \\
\text { identification }\end{array}$ & $\begin{array}{c}\text { Motivation is aligned with } \\
\text { personal identifications }\end{array}$ & $\begin{array}{r}\text { I think waste } \\
\text { separation is useful. }\end{array}$ \\
\cline { 2 - 4 } & $\begin{array}{c}\text { Integrated regulation } \\
\text { Behaviour is governed by } \\
\text { integrated regulations but is } \\
\text { done to gain personal goals }\end{array}$ & $\begin{array}{r}\text { I separate because I } \\
\text { value the } \\
\text { environment. }\end{array}$ \\
\hline Intrinsic \\
Motivation & Intrinsic regulation & $\begin{array}{c}\text { Self-motivated and self- } \\
\text { determined behaviour, driven by } \\
\text { amusement and enjoyment }\end{array}$ & $\begin{array}{c}\text { I separate my waste as } \\
\text { I enjoy doing it. }\end{array}$ \\
\hline
\end{tabular}

In the next section, we describe the drivers of waste separation behaviour. Following, we present the intervention strategies that could be utilised to motivate citizens. In the end, we will elaborate on how those strategies can be used for different citizen profiles of waste separation behaviour.

\section{DRIVERS OF WASTE SEPARATION BEHAVIOUR}

For interventions to be effective, it is essential to portray the drivers of waste separation behaviour drivers. This section elaborates on these drivers in the order of (1) convenience, (2) norms, (3) personal beliefs and values.

\subsection{Convenience}

Citizens evaluate the convenience of waste separation based on the perceived effort (Bernstad et al., 2013; Miafodzyeva and Brandt, 2013; Timlett and Williams, 2011; Varotto and Spagnolli, 2017), perceived difficulty (Miafodzyeva and Brandt, 2013), and space (Bernstad et al., 2013) that the waste separation requires (Varotto and Spagnolli, 2017). When individuals think that waste separation requires too much effort or it is too challenging to perform, they tend to be less motivated. Both perceived difficulty and perceived effort depend on the number of steps that waste separation requires. The more steps it needs, the more complex and effortful it is perceived. This perception can be reversed with knowledge of the consequences of behaviour. Waste separation can be perceived to be more convenient for individuals who have prior recycling experience. Convenience also helps to improve the quality of waste separation when the perceived required effort is decreased.

\subsection{Norms}

Individuals' environmental beliefs and values influence their norms and motivation to separate waste. Some people think that recycling positively influences their personal norms (Geiger et al., 2019; Miafodzyeva and Brandt, 2013). When individuals feel they ought to separate waste, they think they behave environmentally responsible (Varotto and Spagnolli, 2017). People with personal norms value the outcome of waste separation and see themselves as a recycler. On the other hand, individuals' need to feel connected to society and get social approval can serve as the drivers of waste separation.

Interestingly, the neighbourhood sizes might affect the social norms and social acceptance (Geiger et al., 2019). People in small neighbourhoods feel more connected compared to bigger and scattered neighbourhoods. Therefore, neighbourhood sizes should be taken into account while designing waste separation interventions. 


\subsection{Personal Beliefs and Values}

Research shows that knowledge on waste separation (e.g., what products should go in which bin, where to dispose the waste, which days of the week the waste is collected), and the reasons and the consequences of environmental problems contribute to an improved waste separation behaviour (Geiger et al., 2019). Therefore, one way to positively influence the citizens' beliefs and values could be to increase their waste separation knowledge. The ways and effects of increasing knowledge are elaborated in section 4.1 .

\section{INTERVENTION STRATEGIES}

According to Steg and Vlek (2009), there are two types of intervention strategies that are effective in the promotion of waste separation behaviour: information strategies (e.g., prompts and information) and structural strategies (e.g., alterations in the physical environment). An informational strategy does not require a change in the context of waste separation. On the other hand, structural approaches require a change in contextual factors, affecting people's perceptions and waste separation motivations.

Stöckli et al. (2018) also describe two intervention strategies: antecedent, which covers informational strategies (e.g., prompts, modelling and commitment), and consequence which covers strategies that focus on altering the target behaviour results (e.g., feedback, rewards, and penalties). Varotto and Spagnolli (2017) offer multiple strategies as well. However, those strategies are not necessarily categorised as changing the context or not. In the following lines, we will combine and elaborate on the strategies that the three studies mentioned above elucidate. It is essential to note that there is no single strategy for all citizens as every citizen differs in their recycling habits and space available in their homes (Willman, 2015).

\subsection{Prompts and Information}

One most commonly used intervention strategy is prompts and information. The information about the waste separation can be provided in written forms (e.g., flyers, brochures, posters, internet, etc.) or given face-to-face (e.g., doorstepping), and can contain factual and persuasive information or reminders (Varotto and Spagnolli, 2017). Rousta et al. (2015) state that using images instead of texts improves the quality of sorted food waste by $10 \%$. Others reported a significant positive effect of providing more information on waste separation behaviour (Linder et al., 2018; Moreland and Melsop, 2014; Rousta et al., 2015). Even though there are success stories, several studies have reported no significant effect for using this strategy (Árnadóttir et al., 2019; Bernstad, 2014; Bernstad et al., 2013; Dupré, 2014). According to Árnadóttir et al. (2019), this might be because the citizens do not read or comprehend the provided information properly.

\subsection{Feedback}

Feedback can be effective if it contains actionable information about waste separation behaviour at personal (e.g. one's past behaviour) and social levels (e.g. comparison with other individuals or groups) (Varotto and Spagnolli, 2017). It significantly increases the commitment to waste separation behaviour (Dupré and Meineri, 2016).

Abrahamse and Steg (2013) and Bandura (1991) state that feedback's success depends on improving perceived self-efficacy. For instance, feedback can be effective when it contains information about similar others' recycling performance, such as households that live in the same neighbourhood. This is because social norms last longer than personal norms and can be activated by efficient feedback (Abrahamse and Steg, 2013; Schultz, 1999). Meanwhile, individual-level comparative feedback also effectively increases the amount of collected waste and decreases contamination (Perrin and Barton, 2001; Timlett and Williams, 2008). This can be acheived through newsletters, websites, or social media.

Earlier studies show that feedback can be time-consuming as it requires continuous behaviour monitoring (Katzev and Mishima, 1992). Individual-level feedback requires personal contact with every potential recycler, which can be very costly (Schultz et al., 1995). In comparison, group feedback can be more affordable and encourage a widespread social norm for recycling (Czajkowski et al., 2019; Nigbur et al., 2010). 


\subsection{Commitment}

Commitments are less common compared to the previously described intervention strategies. In this type of intervention, residents sign a contract to collectively commit a particular goal (Varotto and Spagnolli, 2017). Research shows that written commitments are more effective than verbal ones (McKenzie-Mohr, 2011), and individual commitments result in an increase in recycling frequency and quality (Dupré, 2014). According to McKenzie-Mohr (2011), group commitment is especially effective when there is good group cohesion. Furthermore, commitment is more effective for people with weak habits than for those who have solid habits (Klöckner and Matthies, 2004). Commitment as a waste separation intervention strategy is challenging to apply at the societal level and can result in refusal to participate (Dupré, 2014; Varotto and Spagnolli, 2017).

\subsection{Social modelling}

Social Cognitive Theory (Bandura, 2001) states that people learn behaviour by observing others. In most cases, individuals imitate a "model" when they find the model relevant to them or believe that imitating the model will result in meaningful and positive outcomes. According to Osbaldiston and Schott (2012), social modelling is effective because it internalises social norms. Thus, demonstrating that others comply with the recycling rules and that every individual's action influences others' compliance can be an efficient intervention. This intervention type's effectiveness depends highly on how much the citizens feel part of the community (Schultz et al., 1995).

\subsection{Incentives}

Incentives give individuals different kinds of benefits (e.g., money, refund, unit pricing programs, gifts, etc.) and encourage them to participate in waste separation programs. Incentives are excellent examples of extrinsic motivation (Geller, 2002). With incentives, individuals perform the behaviour for the sake of extrinsic reward (Burn 1991). The use of incentives is more effective on individuals than on groups, while they are less effective when there is high affluence. Studies show that incentives result in a significant increase in the number of recyclables (Iyer and Kashyap, 2007) and set out participation rates (Harder and Woodard, 2007). According to Iyer and Kashyap (2007), incentives are a great way to encourage short-term output behaviour. Incentives have several disadvantages. It requires continuous monitoring of behaviour, costs outweighing the benefits, and the participants' behaviour can go back to baseline after the incentive program is terminated. Still, incentives can work well over time, even if the initial participation rate is low (Harder and Woodard, 2007).

\subsection{Alterations to the physical environment}

Bernstad (2014) suggests that convenience is essential in compliance with waste separation behaviour. Studies show that increasing the number and decreasing the proximity of recycling bins affect the perceived convenience and improves recycling behaviour (Bernstad, 2014; Rousta et al., 2015). For instance, placing food waste recycling bins in living environments works as a trigger of recycling (NVRD, 2019; Willman, 2015) and can result in habitual waste separation and recycling behaviour.

\section{CITIZEN PROFILES OF WASTE SEPARATION BEHAVIOUR}

To better understand citizens' waste separation behaviour, we propose an initial citizen-profiling framework by combining intervention strategies and drivers of waste separation behaviour, with behaviour regulation types of SDT (Figure 1). This framework aims to explain citizens' waste separation behaviour based on (1) motivational subsystems (i.e., a-motivation, intrinsic and extrinsic motivation), (2) regulation types and basic psychological needs (i.e., SDT and adjunct-theories), and (3) drivers that lead to internalisation of waste separation behaviour (i.e., driver groups).

While forming the framework, we addressed the challenges of different behaviour regulations and elaborated on how the drivers of waste separation behaviour could trigger motivation. Acknowledging the behaviour's complexity, we manifest that promoting the waste separation should address more than one behaviour driver depending on citizens' motivational rivers. To make this complex behaviour more understandable, we grouped the drivers into three groups: personal motivation (coloured in light purple), social motivation (coloured in beige), and convenience (coloured in green). Personal beliefs and values are specifically focused on in the personal motivation group. The norms are reflected in both personal and social motivation groups. 


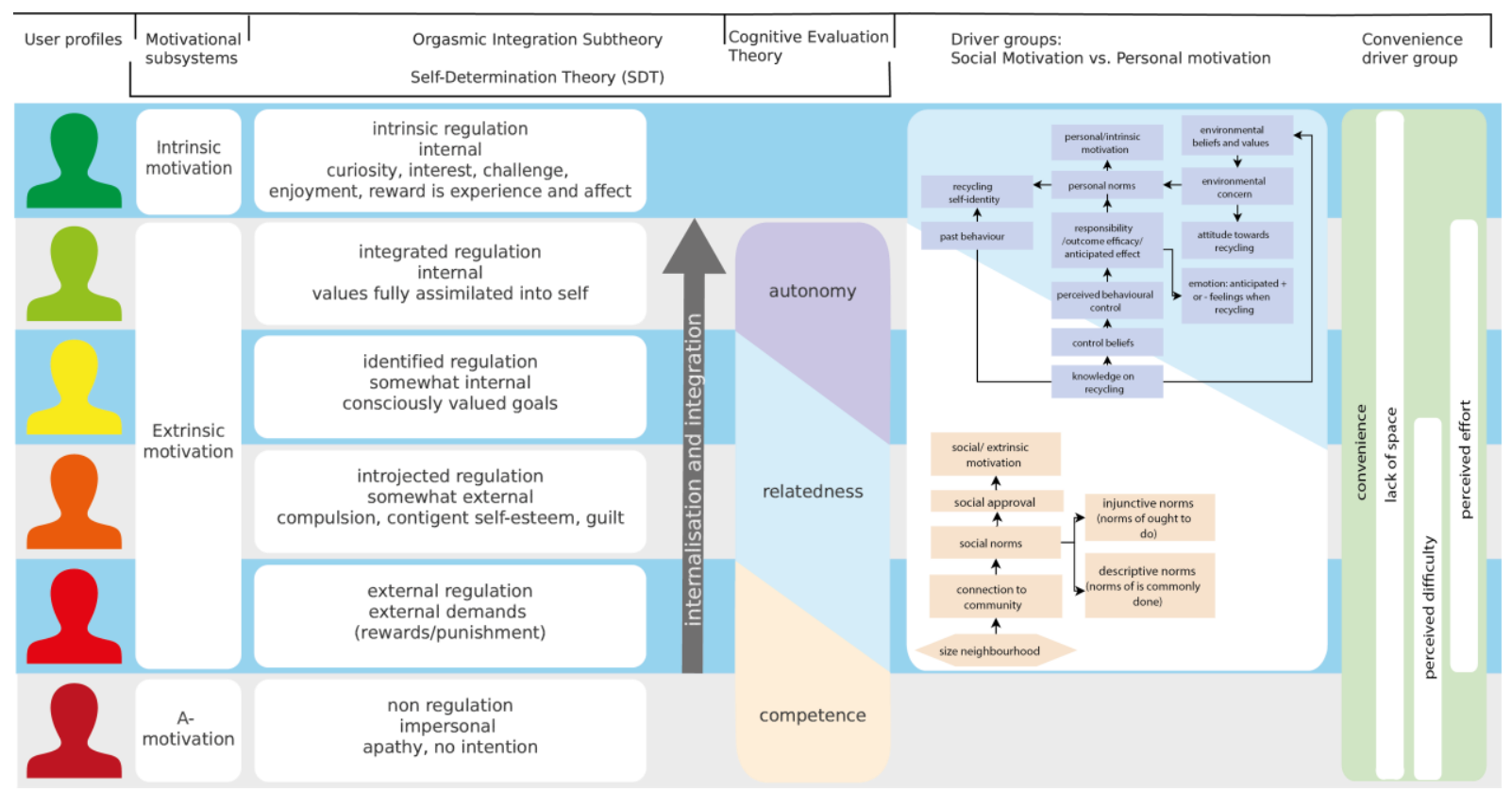

Figure 1. The developed citizen-profiling framework based on the SDT.

We propose that due to the nature of behaviour regulation types, non-regulated and externally regulated groups lack competence, and future interventions should foster competence. Relatedness should be the focus of intervention strategies for the external regulated group. Feeling related is crucial for introjected and identified regulation groups as well, as these groups are somehow motivated by external and social factors. On the other hand, for the integrated regulation group, internal values are fully assimilated to self, and therefore feeling autonomy is of high importance for this group. Our analysis shows that social motivation is possible to transfer into personal motivation. Consequently, it would be wise to focus more on enhancing externally regulated groups' social motivation.

For all citizens, convenience is somehow essential. For extrinsically motivated citizens, the perceived difficulty of waste separation will be greater. However, for citizens living in high-rise buildings, the lack of space will not change over time unless they move to low-rise buildings. Consequently, future interventions should consider lack of space as a barrier to waste separation. Once again, we admit that different motivation types can require various motivation drivers. The following section will discuss how design could utilise different intervention strategies to promote citizens' waste separation behaviour.

\section{DIscussions}

In this paper, we presented the citizen-profiling framework, which we developed in light of the SelfDetermination Theory (Deci and Ryan, 1980). SDT has been an excellent source for our framework due to its elaborate explanation of motivation types and behaviour regulation. We acknowledge that internalisation of motivation is essential for the long-term effectiveness of intervention strategies. However, we did not incorporate the intervention strategies into our framework on purpose. We think that the intervention strategies could alter with new developments and studies that address the challenges of citizens' waste separation behaviour. Still, to give the design community an overview of how the strategies can be implemented, in the following lines, we will discuss the intervention strategies that could accompany the needs of citizens we profiled in the previous section.

\subsection{Prompts and Information}

We think that prompts and information about the environmental problems are useful for all citizen profiles. The information can be effective in enhancing competence for the non-regulation citizen group. Information can highlight the effects of not-separating waste and thus reduce the belief of nonrelationship between behaviour and outcome (Deci and Ryan, 1980). The external regulated group's competence may be improved by showing them the effects of their not-separating behaviour or informing them about what and how of waste separation. Information on what happens to the collected waste will enhance the relatedness needs of external, introjected, and identified regulation citizen groups (Deci and Ryan, 2004). Providing information about the environmental problems (e.g., effects 
of (not) recycling) can enhance identified and integrated regulation groups' autonomy and improve waste separation behaviour.

\subsection{Feedback}

Similar to prompts and information, feedback on historical data will be useful for all citizen groups. This intervention strategy fits non-regulation very well, for the same reason as with prompts and information. For the external regulation group, positive feedback could be effective in enhancing competence.

Feedback on social data can be especially effective for external, introjected, and identified regulation citizen groups. These groups are motivated by comparing their behaviour to that of significant others and would act based on relating themselves to others. We think that social comparison feedback is not effective for the non and integrated regulation citizen groups because social motivation is not their primary reason to act. Feedback can enhance the autonomy of the identified and integrated regulation groups, if it increases the citizens' curiosity about the outcome results of their behaviour.

\subsection{Commitment}

We propose that commitment might not be effective for the non-regulation citizen group, because this group's effort barrier can be very high. Using an external regulation strategy has a better chance of success when framed as an optimal challenge (Deci and Ryan, 2004). Commitment fits the external and introjected regulation citizen groups very well, as commitments are based on external and social motivation. The commitment period should be short for the external regulation citizen group to lower their effort barrier. Finally, we think that commitment is not efficient for the identified and integrated regulation citizen groups, because they might perceive that their autonomy is undermined by signing a contract. These groups would not like the feeling that they have no choice.

\subsection{Social Modelling}

Social modelling focuses mainly on social aspects. A social model can enhance both non-andexternally regulated citizens' competence. According to Deci and Ryan (2004), a good way to strengthen competence is to give positive feedback. This can also be applied in this social modelling by letting citizens showcase their behaviour to the social model and receive the model's feedback. According to our analysis, social modelling could enhance introjected and identified regulated citizen groups' relatedness and autonomy needs.

Since the integrated regulation group values their autonomy, the social modelling strategy is not adequate for them. The same reason holds the ineffectiveness of this strategy for the external-and nonregulation. It is essential to use social models that are relatable for these two groups to reduce the barriers of perceived effort that behaviour requires and perceived difficulty of performing the behaviour.

\subsection{Incentives}

The incentive is a challenging strategy to internalise and integrate motivation and regulation since it is an external reward. In other words, it externalises the motivation (Deci and Ryan, 2004; Pelletier and Sharp, 2008). Enhancing citizen groups' basic psychological needs will not be enough to counteract the externalising effect of incentives. However, incentives might work for the non-regulation and the external regulation citizen groups if the incentives are kept long enough to create a habitual waste separation behaviour.

\subsection{Alterations in the physical environment}

Environmental alterations can be broadly applied and be adapted for all citizen groups. It fits external regulation along with identified and integrated regulation for different reasons. For non-and-external regulation groups of citizens, the environmental alteration can focus on the perceived competence by creating a positive feedback moment when one disposes of items (e.g., a sound in the bin when the waste is (in)correctly disposed of). Another way for non-regulation could be using force that makes it more challenging to perform the undesired behaviour. The relatedness need of external through identified regulation can be enhanced with this intervention strategy by providing an inclusive environment, such as a waste separation game that the households can participate in. Autonomy could 
be enhanced for the identified and integrated regulation groups by providing knowledge in-place (e.g., stickers on the bins that provide information on recycling rules).

\section{CONCLUSIONS}

Climate change has already affected the planet earth with drastic regional and global changes. To reduce the effects of human beings on this, governments seek ways to reduce carbon emissions (Beylot and Villeneuve, 2013; Istrate et al., 2020) and the amount of residual waste (Rousta et al., 2015). There are already several attempts to accomplish this global goal (e.g., no waste challenge as explained in https://www.whatdesigncando.com/nowastechallenge/). Still, reducing global waste requires improvement in the citizens' household waste separation practices (Rousta et al., 2015). In this paper, we articulated citizens' motivations for waste separation behaviour and the strategies that could guide design studies for promoting this behaviour. For this purpose, we proposed a citizen-profiling framework. We suggest that this framework could guide future studies of designing interventions for promoting waste separation behaviour.

Our analysis shows that waste separation behaviour is complicated due to the interplay between various involved and interwoven factors. We admit that this societal challenge cannot be solved with single-solutions. To address this challenge, we proposed intervention strategies that could work for different citizen profiles. Our analysis shows that different strategies can be combined to design an intervention to increase the quality of citizens' waste separation behaviour.

The Citizen-profiling framework is based on our exploration of the profiles in the light of SelfDetermination Theory and its adjunct theories. The framework, therefore, should be regarded as the initial tool for exploring the design opportunities. We suggest researchers expand our framework with participant studies and investigate the relations between different parts of the framework. We believe that the citizen profiles we proposed in this paper must be tested in different regions and cultures. The same holds for the fit between the SDT and the intervention strategies we presented. Future studies can address the effects of joint-strategies on the quality of waste separation.

\section{REFERENCES}

Abrahamse, W. and Steg, L. (2013), "Social influence approaches to encourage resource conservation: A metaanalysis", Global Environmental Change, Pergamon, Vol. 23 No. 6, pp. 1773-1785.

Árnadóttir, Á.D., Kok, G., van Gils, S., and Ten Hoor, GA (2019), "Waste separation in cafeterias: A study among university students in the Netherlands", International Journal of Environmental Research and Public Health, Vol. 16 No. 1, available at: https://doi.org/10.3390/ijerph16010093.

Bandura, A. (1977), "Self-efficacy: toward a unifying theory of behavioural change.", Psychological Review, American Psychological Association, Vol. 84 No. 2, p. 191.

Bandura, A. (1991), "Social cognitive theory of moral thought and action", W. M. Kurtines \& J. L. Gewirtz (Eds.), Handbook of Moral Behavior and Development (Vol., Vol. 1, pp. 45-103.

Bandura, A. (2001), "Social Cognitive Theory of Mass Communication", Media Psychology, No. 3:3, pp. $265-299$.

Bernstad, A. (2014), "Household food waste separation behavior and the importance of convenience", Waste Management, Elsevier Ltd, Vol. 34 No. 7, pp. 1317-1323.

Bernstad, A., La Cour Jansen, J. and Aspegren, A. (2013), "Door-stepping as a strategy for improved food waste recycling behaviour-Evaluation of a full-scale experiment", Resources, Conservation and Recycling, Vol. 73, pp. 94-103.

Beylot, A. and Villeneuve, J. (2013), "Environmental impacts of residual Municipal Solid Waste incineration: A comparison of 110 French incinerators using a life cycle approach", Waste Management, Pergamon, Vol. 33 No. 12, pp. 2781-2788.

Biesbroek, G.R., Swart, R.J., Carter, T.R., Cowan, C., Henrichs, T., Mela, H., Morecroft, M.D., et al. (2010), "Europe adapts to climate change: Comparing National Adaptation Strategies", Global Environmental Change, Pergamon, Vol. 20 No. 3, pp. 440-450.

Burn, SM (1991), "Social Psychology and the Stimulation of Recycling Behaviors: The Block Leader Approach", Journal of Applied Social Psychology, Vol. 21 No. 8, pp. 611-629.

Czajkowski, M., Zagórska, K. and Hanley, N. (2019), "Social norm nudging and preferences for household recycling”, Resource and Energy Economics, Vol. 58, available at:https://doi.org/10.1016/j.reseneeco.2019.07.004.

Deci, EL (1975), “Intrinsic motivation”, New York: Plenum. 
Deci, E.L., Cascio, W.F. and Krusell Judeth. (1975), “Cognitive Evaluation Theory and Some Comments on the Calder and Staw Critique”, Journal of Personality and Social Psychologyand Social, Vol. 31 No. 1, pp. 81-85.

Deci, EL and Ryan, R.M. (1980), "Self-determination theory: When mind mediates behavior.”, Journal of Mind and Behavior, Vol. 1 No. 1, pp. 33-43.

Deci, EL and Ryan, R.M. (1985), "Cognitive evaluation theory", Intrinsic Motivation and Self-Determination in Human Behavior, Springer, pp. 43-85.

Deci, EL and Ryan, R.M. (2004), Handbook of Self-Determination Research, University Rochester Press.

Deci, EL and Ryan, R.M. (2008), "Self-determination theory: A macrotheory of human motivation, development, and health", Canadian Psychology, Vol. 49 No. 3, pp. 182-185.

Dupré, M. (2014), "The comparative effectiveness of persuasion, commitment and leader block strategies in motivating sorting", Waste Management, Vol. 34 No. 4, pp. 730-737.

Dupré, M. and Meineri, S. (2016), "Increasing recycling through displaying feedback and social comparative feedback", Journal of Environmental Psychology, Elsevier, Vol. 48, pp. 101-107.

Eurostat. (2020), "Municipal waste statistics", available at:https://doi.org/ISSN 2443-8219.

Geiger, J.L., Steg, L., van der Werff, E. and Ünal, A.B. (2019), “A meta-analysis of factors related to recycling”, Journal of Environmental Psychology, available at:https://doi.org/10.1016/j.jenvp.2019.05.004.

Geller, E.S. (2002), "The challenge of increasing proenvironmental behavior", R. B. Bechtel, \& A. Churchman (Eds.), Handbook of Environmental Psychology, pp. 525-540.

Harder, M.K. and Woodard, R. (2007), "Systematic studies of shop and leisure voucher incentives for household recycling”, Resources, Conservation and Recycling, available at:https://doi.org/10.1016/j.resconrec.2006.12.001.

Istrate, I.R., Galvez-Martos, J.L. and Dufour, J. (2020), “The impact of incineration phase-out on municipal solid waste landfilling and life cycle environmental performance: Case study of Madrid, Spain”, Science of the Total Environment, Elsevier BV, Vol. 755, p. 142537.

Iyer, E.S. and Kashyap, R.K. (2007), "Consumer recycling: role of incentives, information, and social class", Journal of Consumer Behaviour, Wiley, Vol. 6 No. 1, pp. 32-47.

Katzev, R. and Mishima, H.R. (1992), “The Use of Posted Feedback to Promote Recycling”, Psychological Reports, available at:https://doi.org/10.2466/pr0.1992.71.1.259.

Klöckner, C.A. and Matthies, E. (2004), "How habits interfere with norm-directed behaviour: A normative decision-making model for travel mode choice", Journal of Environmental Psychology, Academic Press, Vol. 24 No. 3, pp. 319-327.

Linder, N., Lindahl, T. and Borgström, S. (2018), "Using behavioural insights to promote food waste recycling in urban households-evidence from a longitudinal field experiment”, Frontiers in Psychology, Vol. 9 No. MAR, pp. 1-13.

McKenzie-Mohr, D. (2011), Fostering Sustainable Behavior: An Introduction to Community-Based Social Marketing, New society publishers.

Miafodzyeva, S. and Brandt, N. (2013), "Recycling behaviour among householders: Synthesising determinants via a meta-analysis", Waste and Biomass Valorisation, Vol. 4 No. 2, pp. 221-235.

Miller, W.R. and Seligman, M.E. (1975), “Depression and learned helplessness in man.”, Journal of Abnormal Psychology, American Psychological Association, Vol. 84 No. 3, p. 228.

Moreland, J. and Melsop, S. (2014), "Design Interventions to Encourage Pro-Environmental Behavior":, No. December, pp. 1-8.

Morlok, J., Schoenberger, H., Styles, D., Galvez-Martos, J.L. and Zeschmar-Lahl, B. (2017), “The impact of pay-as-you-throw schemes on municipal solid waste management: The exemplar case of the county of Aschaffenburg, Germany”, Resources, Vol. 6 No. 1, available at:https://doi.org/10.3390/resources6010008.

Nigbur, D., Lyons, E. and Uzzell, D. (2010), "Attitudes, norms, identity and environmental behaviour: Using an expanded theory of planned behaviour to predict participation in a kerbside recycling programme", British Journal of Social Psychology, Vol. 49 No. 2, pp. 259-284.

NVRD. (2019), "Benchmark Huishoudelijk Afval Peiljaar 2018”, available at: https://www.vanghha.nl/@152607/analyse-benchmark/.

Osbaldiston, R. and Schott, J.P. (2012), "Environmental sustainability and behavioral science: Meta-analysis of proenvironmental behavior experiments", Environment and Behavior, Vol. 44 No. 2, pp. 257-299.

Pelletier, L.G. and Sharp, E. (2008), "Persuasive communication and proenvironmental behaviours: How message tailoring and message framing can improve the integration of behaviours through self-determined motivation", Canadian Psychology, Vol. 49 No. 3, pp. 210-217.

Perrin, D. and Barton, J. (2001), "Issues associated with transforming household attitudes and opinions into materials recovery: A review of two kerbside recycling schemes", Resources, Conservation and Recycling, Vol. 33 No. 1, pp. 61-74.

Rotter, J.B. (university of conneticut). (1966), "Generalised expectancies for interna 1 versus externa 1 control of reinforcement”, Psychological Monographs: General and Applied, Vol. 80 (1) No. 1. 
Rousta, K., Bolton, K., Lundin, M. and Dahlén, L. (2015), "Quantitative assessment of distance to collection point and improved sorting information on source separation of household waste", Waste Management, Elsevier Ltd, Vol. 40 No. 2015, pp. 22-30.

Ryan, R.M. and Connell, J.P. (1989), "Perceived Locus of Causality and Internalization: Examining Reasons for Acting in Two Domains", Journal of Personality and Social Psychology, Vol. 57 No. 5, pp. 749-761.

Ryan, R.M. and Deci, EL (2000), "Self-Determination Theory and the Facilitation of Intrinsic Motivation, Social Development, and Well-Being", American Psychologist, Vol. 55 No. 1, pp. 68-78.

Schultz, P.W. (1999), "Changing behavior with normative feedback interventions: A field experiment on curbside recycling”, Basic and Applied Social Psychology, Vol. 21 No. 1, pp. 25-36.

Schultz, P.W., Oskamp, S. and Mainieri, T. (1995), "Who recycles and when? A review of personal and situational factors", Journal of Environmental Psychology, Vol. 15 No. 2, pp. 105-121.

Steg, L. and Vlek, C. (2009), "Encouraging pro-environmental behaviour: An integrative review and research agenda", Journal of Environmental Psychology, Vol. 29 No. 3, pp. 309-317.

Stöckli, S., Niklaus, E. and Dorn, M. (2018), "Call for testing interventions to prevent consumer food waste", Resources, Conservation and Recycling, Elsevier BV, 1 September.

Timlett, R. and Williams, I.D. (2011), “The ISB model (infrastructure, service, behaviour): A tool for waste practitioners", Waste Management, Vol. 31 No. 6, pp. 1381-1392.

Timlett, R.E. and Williams, I.D. (2008), "Public participation and recycling performance in England: A comparison of tools for behaviour change", Resources, Conservation and Recycling, Vol. 52 No. 4 , pp. 622-634.

Varotto, A. and Spagnolli, A. (2017), "Psychological strategies to promote household recycling. A systematic review with meta-analysis of validated field interventions", Journal of Environmental Psychology, Academic Press, 1 August.

Willman, K.W. (2015), "Information sharing and curbside recycling: A pilot study to evaluate the value of doorto-door distribution of informational literature", Resources, Conservation and Recycling, Elsevier, Vol. 104, pp. $162-171$. 